\title{
BMJ An analysis of the content and clinical open implications of online advertisements for female genital cosmetic surgery
}

\author{
Lih-Mei Liao, Neda Taghinejadi, Sarah M Creighton
}

To cite: Liao L-M,

Taghinejadi N, Creighton SM. An analysis of the content and clinical implications of online advertisements for female genital cosmetic surgery. BMJ Open 2012;2: e001908. doi:10.1136/ bmjopen-2012-001908

- Prepublication history for this paper are available online. To view these files please visit the journal online (http://dx.doi.org/10.1136/ bmjopen-2012-001908).

Received 6 August 2012 Accepted 5 October 2012

This final article is available for use under the terms of the Creative Commons Attribution Non-Commercial 2.0 Licence; see http://bmjopen.bmj.com
UCL Elizabeth Garrett Anderson Institute of Women's Health, University College Hospital, London, UK

Correspondence to Sarah M Creighton; sarah. creighton@uclh.nhs.uk

\section{ABSTRACT}

Objectives: Women who are contemplating any form of female genital cosmetic surgery (FGCS) are likely to seek information from provider websites. The aim of this study is to examine the breadth, depth and quality of clinical information communicated to women on 10 popular sites and to discuss the implications of the results.

Methods: The content of online advertisement from 10 private providers that offer FGCS procedures was examined according to 16 information categories relating to indications for surgery, types of procedure, risks and benefits.

Results: FGCS procedures were presented on all of the provider websites as an effective treatment for genital appearance concerns. No explanation for presenting clinical complaints was found. There was scanty reference to appearance diversity. Only minimal scientific information on outcomes or risks could be identified. There was no mention of potential alternative ways for managing appearance concerns or body dissatisfaction.

Conclusions: The quality and quantity of clinical information in FGCS provider sites is poor, with erroneous information in some instances. Impeccable professionalism and ethical integrity is crucial for this controversial practice. Clear and detailed guidelines on how to raise the standard of information to women on all aspects of FGCS are urgently needed.

\section{INTRODUCTION}

A variety of operations to alter vulval morphology in the absence of medical indications is currently offered ${ }^{1}$ and easily accessed in the private sector. Female genital cosmetic surgery (FGCS) encompasses numerous surgical procedures including hymenoplasty, labiaplasty, 'G-spot' amplification and vaginal 'rejuvenation'. In 2007, the American College of Obstetricians and Gynecologists became sufficiently concerned to issue a statement to practitioners warning that 'these procedures are not medically indicated and the safety and effectiveness of these procedures have not been documented'. 'The

\section{ARTICLE SUMMARY}

Article focus

- A content analysis of the clinical information in web-based advertisements for female genital cosmetic surgery (FGCS), focusing on 10 easily accessed provider websites.

Key messages

- No lower age limit is stated for any of the elective procedures.

- Information pertaining to the unknowns and to the anecdotal nature of clinical claims is missing.

- Numerous labels pertaining perhaps to similar procedures may confuse consumers.

Strengths and limitations of this study

- This is the first study to methodically examine the quality of information offered by FGCS providers. In using a single search engine (Google) and a single popular search term (designer vagina), the report provides only an initial snapshot of the online exposure that women and girls worried about their genital characteristics may access via provider sites.

level of clinical debate is reflected in the rising number of commentaries and discussion papers that can be identified in the medical literature. ${ }^{2}$ The bioethics of medical marketing of cosmetic surgery are increasingly the subject of scholarly analysis in nonmedical humanities literatures. ${ }^{3}$ Public concerns are reflected in social and artistic projects in popular culture to counter negative stereotypes of the natural vulva. ${ }^{4-6}$

Various reasons have been put forward to explain this new cultural phenomenon in which medicine is deeply implicated. One important potential reason is direct marketing to consumers rather than via referrals by health professionals. ${ }^{3} 78$ In our digital age, such marketing will rely heavily on the internet. Women and girls seeking surgery to alter the appearance of their labia often report having visited such sites for 
information. ${ }^{9}$ To date, there has been scant attention paid to information contained in medical provider advertisements for FGCS. A previous analysis explored the use of language and photographs to pathologise genital variance in online advertisements and concluded that the sites employed a range of medical, psychological and sexual truth-claims. ${ }^{10}$

Thus far, there has been no medical scrutiny of the quantity and quality of the clinical information on what is after all elective surgery with known risks. Even cosmetic surgeons themselves have drawn parallels between the practice and the 'old Wild Wild West: wide open and unregulated'. ${ }^{11}$ The purpose of this study is to describe how FGCS procedures are represented in medical services websites by examining the accuracy of the medical information provided.

\section{METHOD}

Websites offering FGCS were identified using the popular search engine 'Google' (http://www.google. com). ${ }^{12}$ Google was chosen as it is consistently ranked as the most popular search engine. In addition, women attending our clinic with labial concerns frequently cite Google as their first choice for seeking information online. The term 'designer vagina' was entered into the search engine, because it is a familiar (if erroneous) term in popular culture. The first five $\mathrm{UK}^{13-17}$ and five $\mathrm{US}^{18-22}$ providers to appear in the search results were included in the study. The only criteria for inclusion were that providers had to offer at least one form of FGCS in either the UK or the USA. There were no exclusion criteria. Ethical approval was not required.

Sixteen information categories were predeveloped by the two senior authors (LML and SMC) for analysing the content of the information, building from the 'Questions to Ask the Surgeon' section of the NHS Choices website. ${ }^{23}$ A key criticism of FGCS has been its status as a non-evidence-based practice; therefore, additional information categories included immediate and long-term potential clinical effectiveness and adverse events. The 16 categories for analysis are given in table 1 with an explanation for each.

Each website was initially evaluated by one of the authors (NT) to confirm suitability for inclusion and to identify and collect information relevant to each category. All websites were then assessed independently by the two senior authors. Ambiguities or disagreement were resolved by discussion between all of the authors. SMC grouped the procedures into types of surgery.

\section{RESULTS}

In 5/10 sites, the term 'cosmetic gynaecology' described the range of services offered. ${ }^{13-15} 1921$ Table 2 contains the listing of the 72 labelled procedures identified across the 10 websites. Non-standard terminology and missing technical descriptions render it impossible to

\section{Table 1 Chosen criteria for analysis of websites}

Criteria What was analysed

1. Types of procedure offered

2. Description of procedure

3. Use of medical rhetoric

4. Symptoms that surgery treats

5 . Benefits of surgery stated or implied

6. Success rates

7. Specific reference to social and psychological advantages

8. Specific reference to enhancement of sexual experience

9. Risks of surgery

10. Absence or presence of a caution section

11. Aftercare

12. Immediate outcomes

13. Long-term outcomes

14. Absence or presence of positive testimonials

15. Absence or presence of 'before' and 'after' images

16. Lowest age limit for surgery
Procedures classified into general types of procedure (if possible)

Information given on surgical technique and other information for example, use of laser

Suggestions that treatment is for a medical condition. Specific use of the term 'labial hypertrophy' as an indication for labiaplasty.

Physical discomfort or appearance concerns

Improve discomfort or appearance. Mention of any other benefits such as hygiene What percentage of women achieve the benefits listed in 5 .

Non medical benefits such as confidence leading to other advantages.

Any mention that sex will be improved for the patient or partner.

Infection and bleeding should be documented as a potential risk of any surgical procedure. Other recognised risks include scarring and dissatisfaction with outcome.

Are consumers advised to think carefully before proceeding to FGCS?

Basic wound hygiene should be given following any genital surgical procedure These would include beneficial outcomes and short-term risks as listed in 9 . These would include beneficial outcomes such as those listed in 5,7 and 8 as well as potential risks listed in 9.

Usually in the form of personal stories about how surgery impacted upon an individual

Photographs 'before' and 'after' were analysed. Some sites contained videos which we did not analyse

Any mention that 16 years is the age of legal consent for surgery 
Table 2 Types of procedures available

\begin{tabular}{|c|c|}
\hline General category of procedure & Operations available \\
\hline Labial surgery & $\begin{array}{l}\text { Labioplasty, labial reduction, labial augmentation, labia design, vaginal lip } \\
\text { reduction, labia majora reduction, liposculpting of labia majora, } \\
\text { combination labioplasty, expert labiaplasty, expert augmentation/ } \\
\text { enlargement of labia majora, laser reduction labioplasty, laser reduction } \\
\text { labioplasty with reduction of thickness of the minora, Designer laser } \\
\text { labiaplasty, stem-iris labial sculpting, laser reduction labiaplasty of the } \\
\text { labia major via extension of perineoplasty, augmentation labioplasty via } \\
\text { fat transfer }\end{array}$ \\
\hline Clitoral Surgery & $\begin{array}{l}\text { Expert clitoral hood reduction, clitoral hood reduction, hoodectomy, } \\
\text { prepuce reduction, reduction excess prepuce }\end{array}$ \\
\hline Vaginal Surgery & $\begin{array}{l}\text { Vaginoplasty, vaginal tightening, vaginal rejuvenation, laser vaginal } \\
\text { rejuvenation, vaginal reshaping, vaginal reconstruction, vaginal } \\
\text { enlargement, vaginal reduction, Designer vagina, vaginal rugae } \\
\text { rejuvenation, Designer laser vaginoplasty }\end{array}$ \\
\hline Hymenal Surgery & $\begin{array}{l}\text { Hymen reconstruction, hymenoplasty, hymen repair, virginity } \\
\text { reconstruction, hymen cosmetic surgery, virginity repair, hymenorraphy, } \\
\text { laser hymenoplasty, hymen restoration }\end{array}$ \\
\hline $\begin{array}{l}\text { Non-specific vulval and perineal surgery (may } \\
\text { include labial surgery but not specified) }\end{array}$ & $\begin{array}{l}\text { Vulvoplasty, perineoplasty, liopscupting, vulval lipoplasty, genitalia } \\
\text { rejuvenation, genital lift, genitoplasty }\end{array}$ \\
\hline Surgery to mons pubis & Liposculpting of mons pubis, mons pubis reduction \\
\hline G-spot & G-spot augmentation, G-spot enhancement \\
\hline
\end{tabular}

decipher the exact number of types of procedures offered, for example, 'vulval reshaping', 'genital reshaping' and 'vulva and vagina rejuvenation'. Different terms may refer to the same procedure, for example, 'hymen repair', 'hymenoplasty', 'hymen reconstruction', and possibly 'revirgination'. The terms 'clitoral hood reduction' and 'prepuce reduction' are also likely to refer to the same technique. The 72 labels probably refer to seven main intervention types. One site uses the terms 'Wonder Woman' and 'Mommy Makeover' to describe women undergoing several simultaneous cosmetic procedures. $^{22}$ The greatest proportion of text was devoted to labia minor reduction. Three sites used the term 'labial hypertrophy' as a reason to undergo this type of surgery. $^{17} 1921$

Table 3 is a summary of the main results. As far as indications for surgery are concerned, aesthetic concerns were mentioned in all of the websites. Aesthetic indications included: labial visibility under tight clothing, women 'made aware by their partner' 16 of larger labia and women themselves 'being more aware of their labia owing to increased nudity in magazines and films' ${ }^{20}$ In several sites, labial surgery was recommended to promote a 'youthful' vulval appearance. ${ }^{13} 18$ One site offered an explanation thus: 'a woman might have a face lift and look really young until she goes to bed and a partner can see the evidence of ageing there'. ${ }^{16}$ Surgery was recommended to make labia 'sleeker'"20 and 'more appealing'. ${ }^{21}$ All of the websites claimed that surgery would improve vulval appearance. Three sites did mention that 'size and shape of labia do vary quite widely'15 1720 and that the labia were 'not naturally symmetrical ${ }^{20}$; however, surgery was recommended nevertheless. Hymenoplasty was recommended to 'improve the woman's hidden aesthetics'20 and to ensure that 'you should bleed on your wedding night and keep your head high'. 16

Nine of the 10 websites mentioned physical indications for surgery and these included discomfort with certain types of clothing, discomfort during intercourse, difficulty with tampon insertion and chronic irritation. Reference to surgery to improve personal hygiene was identified in $3 / 10^{22}$ websites $^{18-20}$ where longer labia were alleged to cause 'odour', yeast infections and possible recurrent urinary tract infections. ${ }^{18}$ Half of the websites also mentioned enhanced sexual pleasure, ${ }^{13-15} \quad 18 \quad 2022$ for example as a result of improved sexual confidence and reduced discomfort during sex. One site claimed that 'sensation may even be enhanced because of the new nerve endings and removal of the tissue'. ${ }^{18}$ One site stated that 'sexual gratification is directly related to the amount of frictional forces generated' (presumably for male partners during vaginal intercourse) and that such 'frictional forces' could be improved by laser vaginal rejuvenation; ${ }^{22} \mathrm{G}$-spot injection was claimed to 'revolutionise many women's sex lives'. ${ }^{13}$

Success rates of $95 \%^{19}$ and $100 \%^{16}$ ('all patients satisfied') were given in $2 / 10$ websites, though there was no information on what constituted success and how the statistics were derived. The remaining eight sites gave no indication of success rates; one site ${ }^{21}$ claimed 'the best results worldwide' and that their surgeon 'has an excellent track record'. Social and psychological advantages were mentioned in all the 10 sites, for example, 'restoration of self-confidence and esteem, ${ }^{13}$ leading to better career prospects in advertising, sport and modelling ${ }^{13}$ as 
Table 3 Summary of results

\begin{tabular}{|c|c|}
\hline Criteria & Findings \\
\hline 1. Types of FGCS offered & $\begin{array}{l}77 \text { different procedures named. All sites offer labiaplasty and vaginoplasty/vaginal } \\
\text { reconstruction. } \\
3 / 10 \text { also offer hymen repair }\end{array}$ \\
\hline 2. Description of procedure & All sites give basic explanation of the surgical procedure \\
\hline 3. Use of medical language & $\begin{array}{l}\text { 3/10 sites refer to 'Labial Hypertrophy' } \\
5 / 10 \text { sites referred to 'Cosmetic Gynaecology' }\end{array}$ \\
\hline 4. Symptoms which surgery treats & $\begin{array}{l}9 / 10 \text { sites claim surgery treats both physical (functional) and aesthetic } \\
\text { (appearance) concerns } \\
1 / 10 \text { sites claim surgery improves appearance and sexual pleasure but no } \\
\text { mention of physical symptoms }\end{array}$ \\
\hline 5. Benefits of surgery implied & $\begin{array}{l}\text { All sites claim improved appearance and relief of discomfort. 4/10 sites claim } \\
\text { surgery improves hygiene }\end{array}$ \\
\hline 6. Success rates & $1 / 10$ claim $100 \%, 1 / 10$ claim $95 \%$ \\
\hline $\begin{array}{l}\text { 7. Specific reference to social advantages } \\
\text { of surgery }\end{array}$ & $\begin{array}{l}\text { 2/10 sites mention social advantage including } \\
\text { - improving career prospects in sport and modelling, } \\
\text { - reduce signs of ageing } \\
\text { - able to wear wider range of clothing } \\
\text { - improved self confidence }\end{array}$ \\
\hline $\begin{array}{l}\text { 8. Specific reference to enhancement of } \\
\text { sexual experience }\end{array}$ & $\begin{array}{l}5 / 10 \text { mention improved sexual relationships and enhanced sexual pleasure for } \\
\text { woman and her partner }\end{array}$ \\
\hline 9. Risks of surgery & All sites mention that surgery has risks \\
\hline 10. Absence or presence of a cautionary & $7 / 10$ offer no cautionary advice \\
\hline advice section & $\begin{array}{l}1 / 10 \text { suggests that 'proper assessment by a gynaecologist is necessary prior to } \\
\text { embarking on surgery' } \\
2 / 10 \text { emphasis the important of careful consideration before surgery }\end{array}$ \\
\hline 11. Aftercare & $\begin{array}{l}\text { All sites give general aftercare advice on hygiene, simple analgesia, resumption } \\
\text { of sexual intercourse etc }\end{array}$ \\
\hline 12. Immediate outcomes & 8/10 sites mention mild discomfort and swelling \\
\hline 13. Long- term outcomes & $\begin{array}{l}\text { No adverse long-term outcome mentioned. All sites refer to non-specific positive } \\
\text { outcomes such as social advantages and enhanced sexual pleasure }\end{array}$ \\
\hline 14. Absence or presence of positive & $3 / 10$ sites contain small numbers $(1-3)$ testimonials from satisfied customers \\
\hline $\begin{array}{l}\text { 15. Absence or presence of before and } \\
\text { after photographs }\end{array}$ & $6 / 10$ contain before and after photographs \\
\hline 16. Lowest age limit for surgery & No site gives a lower age limit for surgery \\
\hline
\end{tabular}

well as improving 'disharmony and resentment' in relationships. ${ }^{13}$ Surgery was said to allow the patient to 'feel like a real woman again' ${ }^{15}$ and was positioned as an expression of personal agency, as in 'ladies, you do NOT have to go on feeling this way'. ${ }^{18}$

All 10 sites mentioned risks to surgery. In 4/10 sites, the risks were not named, but an offer was made regarding a risk discussion with the surgeon prior to surgery. ${ }^{14-16} 21$ The remaining 6/10 sites gave lists of common surgical risks including haemorrhage and infection. These were usually described as uncommon claiming 'no complications or side effects with any of our patients' and 'pregnancy is associated with far more risk than these procedures'. ${ }^{18}$ Two sites mentioned scarring as a risk and 1/10 mentioned that 'surgery on the labia minor may alter the appearance of the clitoris in an undesirable way'. ${ }^{13}$ One site gave a rate of approximately $2 \%$ revision rate for vaginal operations. ${ }^{18}$ Revision rate was not mentioned for other operations or in any of the rest of the sites. Three sites mentioned 'botched labiaplasties' performed by other providers causing disfigurement ${ }^{16}$ and requiring revision, ${ }^{16} \quad 18 \quad 21$ for example, 'we have seen many unfortunate examples of terrible scarred uneven results of labiaplasty from other physicians'. ${ }^{21}$ No site mentioned any postoperative dissatisfaction in any of their own patients. There was no reference to short-term and long-term outcomes of surgery based on actual data.

Six sites posted photographs before and after labiaplasty. $^{13}{ }^{18-22}$ In all cases, the 'before' pictures represented larger normal labia whereas all postoperative pictures showed a homogenised vulval appearance. Three sites gave positive personal testimonials, for example, 'Now I have such a sense of freedom. I'm no longer restricted by discomfort and can cycle 2 days running without feeling sore'. 14

None of the 10 sites gave a lower age limit for surgery. One site did provide a consent form which the patient had to be over 18 to sign but did not state whether an adult can do this on the patient's behalf. ${ }^{22}$ 


\section{DISCUSSION}

This content analysis according to 16 information categories is the first ever attempt to methodically evaluate the quality of information offered by FGCS service providers. Although this is a snapshot analysis at a single time point of websites that may be regularly updated, it does offer a glimpse of what many women and girls are exposed to if they are worried about their genitals and/ or are seeking interventions. Although there is certainly some positive information on the web for women with labial concerns, ${ }^{24}$ this can be more difficult to find and certainly does not feature in the most popular sites when enquiring about labial surgery.

A search based on one term and using one search engine is, of necessity, a basic evaluation and may mirror only the initial search performed by worried women (and probably girls). The advertisements accessed by individuals will differ. Given the secrecy surrounding labial concerns, women are likely to seek this information at home. Google displays advertisements based on previous websites viewed, as well as known interests and demographic details associated with a specific browser. Google states that they do not create categories or show advertisements based on sensitive topics which include health. It is unclear whether this would include cosmetic surgery websites. Despite these limitations, the similarity of information found on the websites analysed in this study would imply such information would be reproduced whichever websites women first came across.

Consumers looking at these sites may be confused by the myriad labels for the procedures and uncertain as to how to determine whether some of them are the same or different from each other. Labiaplasty may well be the most popular operation, in view of the relatively higher proportion of text devoted to the topic. The term 'labial hypertrophy' reflects a rhetorical claim, as it is not rooted in science. Despite an absence of increase in identifiable labial pathology, more and more articles have described new techniques for managing this supposed disease.

Most of the sites documented short-term risks such as infection and bleeding and some mentioned the possibility of revision. However, the risks were often minimised (eg, lower than pregnancy). ${ }^{18}$ The absence of evidence for clinical effectiveness was not only left out, but in combination the sites actually made scientifically inaccurate claims that the procedures were effective along physical, psychological, social and sexual parameters. To date, there are no well-planned long-term prospective studies on multiple long-term outcomes of FCGS procedures. Any claim alluding to clinical effectiveness is therefore unsubstantiated. A recent detailed qualitative analysis suggested that consumers may have unrealistic ideas about labiaplasty. ${ }^{25}$ In view of the how FGCS was presented in the 10 provider sites, this should not come as a surprise.

The absence of a lower age limit for any of the FGCS procedures is most disturbing of all. In the past 6 years,
343 labiaplasties were performed in the UK NHS on girls aged 14 or under. ${ }^{26}$ The indications for surgery in this group of children are unknown, but labial anomalies requiring surgical interventions are extremely rare. In addition, significant numbers of labiaplasties on girls under 18 years of age are reported in the medical literature with publications dwelling specifically on labial reductions in adolescents for hypertrophy or asymmetry of the labia minora. ${ }^{4}$ In a recent observational study of referral patterns, girls as young as 9 years with normal labia had presented for labiaplasty. ${ }^{27}$ The labia minora change as part of normal pubertal growth with development completed as the individual approaches adulthood. Given the fact that anatomy continues to change throughout the lifespan, the younger a girl begins her FGCS journey, the higher the number of lifetime operations and the greater and more multiple the risks.

The 'before' photographs echo the finding in a recent report that most women seeking labiaplasty have labial dimensions that fall within normal limits. ${ }^{11}$ Negative connotations for larger labia such as ugliness, odour and irritation are strongly implied in the advertisements. Such negative connotations may reinforce "pudendal disgust $^{428}$ that is likely to encourage negative feelings towards the vulva. Negative thoughts and feelings can in turn exacerbate symptom experience and reporting. The 'after' photos promote a suspiciously narrow appearance norm, that is, a smooth-skinned vulva with invisible labia minora. Findings from this study echo previous concerns that these sites employ a variety of techniques which aim to 'educate' women about the surgical solutions to potentially unknown defects in their bodies. ${ }^{11}$

Physical discomfort such as chafing and irritation may be partly attributable to genital grooming and is, as already discussed, potentially exacerbated by negative thoughts and feelings about the vulva. The discomfort may be addressed by simple measures such as emollients, as opposed to surgery. It is well to remember that both men and women may experience genital discomfort, but only women are encouraged to have their external genitalia excised as a solution. Psychological complaints such as self-consciousness, anxiety and lack of sexual confidence are more appropriately addressed by psychological interventions. Providers should emphasise that healthy vulvas come in all shapes, sizes and colours, that all vulval appearances are compatible with psychological and sexual wellness, and that the majority of women do not choose to surgically alter their healthy vulva.

The psychological effects of exposure to the myriad elective procedures to the vulva would make an interesting focus for future studies. A woman who is somewhat self-conscious about her labia may suddenly discover her other vulval inadequacies, such as a lax vagina that is failing male partners with insufficient 'frictional forces' ${ }^{21}$ The encouragement of such cultural stereotypes is unlikely to be helpful to women or men.

Provider websites are of course not the only contributors to online representations of the idealised or the 
demonised vulva. Women may be as likely to refer to pornography, blogs and forums for information and selfcomparison. Nevertheless, this report highlights a certain degree of distortion to information provided by medical practitioners, in an area that is imbued with value judgement. Current measures taken by professional bodies to provide guidance seem ineffectual. ${ }^{29} \mathrm{It}$ is surely preferable for medical authorities to professionally govern medical practices than to risk external interventions, for example by the Advertising Standards Authority.

\section{CONCLUSION}

This study is an initial clinical evaluation of online advertisement for FGCS. While the 10 websites analysed are small in number, the findings offer useful glimpses into the quality of information for the potential consumer and have implications for clinical standards. The terminology used to describe the operations performed is confusing. Little information is given on short-term or long-term surgical risks either from individual clinics and their surgeons or from the medical literature. Unsubstantiated claims of physical, psychological and sexual benefits were present on every website. This report highlights significant gaps in the breadth, depth, accuracy and quality of clinical information given by some service providers of FGCS.

Contributors SMC and LML conceived and designed the study. NT performed initial search and data collection. SMC and LML assessed all websites. SMC, LML and NT contributed to writing the paper.

Funding None.

Competing interests None.

Provenance and peer review Not commissioned; externally peer reviewed.

Data sharing statement No further data are available.

\section{REFERENCES}

1. American College of Obstetricians and Gynecologists Committee Opinion. No. 378: vaginal 'rejuvenation' and cosmetic vaginal procedures. Obstet Gynecol 2007;110:737.

2. Liao LM, Michala L, Creighton SM. Labial surgery for well women: a review of the literature. BJOG 117:20-5.

3. Tiefer L. Female cosmetic genital surgery: freakish or inevitable. Analysis from medical marketing, bioethics and feminist theory. Feminism Psychol 2008;18:466-79.

4. www.thecentrefoldproject.org

5. www.greatwallofvagina.co.uk

6. http://ukfeminista.org.uk/events/muff-march

7. Liao LM, Creighton SM. Requests for cosmetic genitoplasty: how should health care providers respond? BMJ 2007;334:1090-92.

8. Braun V. Female genital cosmetic Surgery: a critical review of current knowledge and contemporary debates. J Womens Health 2012;19:1393-407.

9. Crouch NS, Deans R, Michala L, et al. Creighton SM Clinical characteristics of well women seeking labial reduction surgery: a prospective study. BJOG 2011;118:1507-10.

10. Braun V. Selling the 'perfect' vulva. In: Heyes C, Jones M, eds. Cosmetic surgery: a feminist primer. Ashgate, Surrey, 2009:133-49.

11. Goodman MP, Female genital cosmetic surgery. Obstet.Gyecol 2009;113:154-9.

12. www.google.com. Accessed in the UK January to August 2012.

13. Gynecosmetics (http://www.gynecosmetics.com)

14. The Harley Medical Group (http://www.harleymedical.co.uk)

15. The Hospital Group (http://www.thehospitalgroup.org)

16. Regency Clinic (http://www.regencyclinic.co.uk)

17. Spire Health Care (http://www.spirehealthcare.com)

18. Cosmetic Gynecology Centre of San Antonio (http://www cosmeticgyn.net)

19. Cosmetic Gynecology Surgery Suite (http://www.vaginalabiaplasty. com)

20. Dr G Cosmetic Surgery (http://www.drgcosmeticsurgery.com)

21. The Labiaplasty Master Surgery Centre of New York. http://www. labiadoctor.com

22. Laser Vaginal Rejuvenation Institute of Los Angeles (http://www. drmatlock.com)

23. http://www.nhs.uk/livewell

24. http://newviewcampaign.org

25. Bramwell R, Morland C, Garden AS. Expectations and experience of labial reduction: a qualitative study. BJOG 2007;114:1493-9.

26. Hospital Episode Statistics. http://www.hesonline.org

27. Deans R, Liao LM, Crouch NS, et al. Why are women referred for female genital cosmetic surgery? MJA 2001;195:99.

28. Braun V, Kitzinger $C$. The perfectible vagina: size matters. Cult Health Sex 2001;3:263-7.

29. American College of Obstetricians and Gynaecologists Committee Opinion Ethical Ways for Physicians to Market a Practice No. 510 Nov 2011. 